\title{
Endoscopic Accessory Device
}

National Cancer Institute

\section{Source}

National Cancer Institute. Endoscopic Accessory Device. NCI Thesaurus. Code C50338.

A supplementary device or component designed to work with an endoscope. 